\title{
Informação não-científica sobre a ciência na dinâmica da informação e da memória
}

DOI: 10.3395/reciis.v3i3.288pt

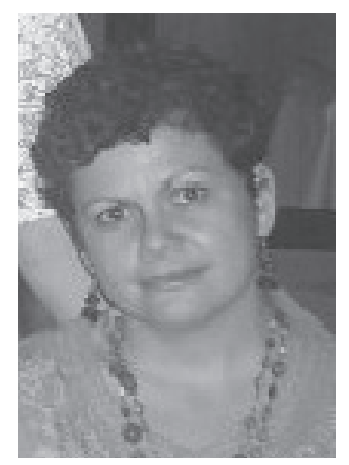

Carmen Irene C. de Oliveira

Programa de Pós-Graduação em Ciência da Informação, Universidade Federal Fluminense, Niterói, Brasil

irecor@brfree.com.br

\section{Resumo}

Trazemos para o campo da ciência da informação questões relacionadas a produtos culturais específicos: filmes de ficção científica. Problematizamos a representação da ciência, no âmbito da ficção e da informação. Pretendemos estabelecer o estatuto de uma informação de natureza ficcional sobre a ciência. Pensamos que a dinâmica da memória do gênero está relacionada à própria dinâmica de uma informação não-científica sobre a ciência. Trabalhamos com remakes (refilmagens) e tomamos cada filme como um momento de uma grande narrativa sobre o referente ciência. A abordagem do conhecimento a partir da criação ficcional, considerando a informação como elemento estruturante de um fenômeno discursivo da cultura cinematográfica, é enfocada no contexto de uma dinâmica cultural e uma práxis de memória. Pressupomos que as refilmagens, ao apresentarem diferentes versões de uma mesma narrativa ficcional, reorganizam os fatos apresentados desde a primeira versão, procurando o equilíbrio entre a novidade e o já (re)conhecido. Apresentamos as análises já empreendidas a partir de dois conjuntos de filmes: Máquina do Tempo (1960; 2002) e Guerra dos Mundos (1952, 2005) tomando o referente, ciência, e o ator e apontamos para algumas características deste tipo de informação.

\section{Palavras-chave}

Informação; informação não-científica; remake; memória; ficção-científica

\section{Introdução}

A nossa investigação procura delinear, no campo da ciência da informação, um tipo de informação denominada por nós de "informação não científica sobre a ciência", a partir do trabalho com produtos culturais específicos, filmes de ficção científica, que possibilitam empreender análises de textos ficcionais sobre a ciência. Tais questões tangenciam a problemática de uma discursividade pautada na linguagem cinematográfica, na injunção com as questões da memória da e para a ciência e sua potencialidade para divulgação. Nesse sentido, trabalhamos com a representação em dois sentidos. O primeiro relaciona-se com a imagem da ciência e seus atores, no âmbito da ficção. O segundo, diz respeito à representação da informação. Tais níveis ou sentidos são denominados, inicialmente, representação no nível ficcional e representação no nível informacional, respectivamente, e acreditamos que entre elas há um incremento mútuo.

Tal empreendimento objetiva estabelecer o estatuto de uma informação de natureza ficcional sobre a ciência a partir destes produtos culturais, indicando a ação de uma memória de gênero (M. Bakhtin) no processo de construção, circulação e consumo dos filmes de sci-fi. 
Trata-se da questão principal de nossa pesquisa, e pensamos que a dinâmica dessa memória do gênero está relacionada à própria dinâmica desse tipo de informação que procuramos estabelecer.

Finalmente, pretendemos apontar a potencialidade dessa informação no âmbito da popularização da ciência, tendo em vista o processo de circulação, no contexto de uma cultura de massa, de formas discursivas ficcionais do pensamento científico, ou seja, de uma ciência ficcionalizada, que toma forma a partir do gênero cinematográfico de sci-fi e que abriga elementos do imaginário tecno-maquínico.

Trabalhamos com produções que se caracterizam por serem remakes e tomamos cada filme como um momento de uma grande narrativa sobre ciência. A palavra remake significa refazer e no âmbito do cinema este termo identifica produções fílmicas que retomam o roteiro de um filme anteriormente produzido para desenvolver sua história. A abordagem do conhecimento a partir da criação ficcional, considerando a informação como elemento estruturante de um fenômeno (remake) da cultura cinematográfica, é enfocada considerando-se uma dinâmica cultural e uma práxis de memória. Pressupomos que as refilmagens, ao apresentarem diferentes versões de uma mesma narrativa ficcional, operam uma transferência que reorganiza os fatos apresentados desde a primeira versão, procurando garantir que em cada texto haja um equilíbrio entre a novidade e o já reconhecido, entre informação e redundância, que conduz ao reconhecimento e ao estranhamento. Apresentamos as análises já empreendidas a partir de dois conjuntos de filmes, formados pela primeira versão e sua refilmagem: Máquina do Tempo (1960; 2002) e Guerra dos Mundos (1952, 2005) tomando como referente a ciência e seu ator, cientista, como pontos pelos quais a informação não-científica dinamiza-se nas narrativas.

\section{As narrativas ficcionais da ciência}

As expressões ficcionais da ciência aqui trabalhadas são as ficções científicas cinematográficas. No entanto, os elementos míticos que elas articulam, assim como as especulações científicas que elas arregimentam, são comuns a outras formas como as narrativas literárias. $\mathrm{O}$ que nos interessa é a articulação entre ciência e ficção e a dinâmica de uma informação de natureza ficcionalizada que também informa sobre ciência.

Nessa discussão, há muito acerca do binômio ciência e mito, destacando-se a perspectiva dos mitos que alimentam ou impulsionam determinados desejos de pesquisa científica. Os denominados mitos dinâmicos, de Abraham Moles (apud LEGROS et al., 2007), são exemplos adequados desses motores do fazer científico. Os mitos dinâmicos seriam "uma tendência organizadora que modula o fluxo das descobertas, orientando de maneira inconsciente os empreendimentos pessoais" (GABRIEL, 2002, p.107). Dentre eles, podemos destacar: o mito de Ícaro (impulsiona o homem a se libertar do peso; como aplicação tem-se a aeronáutica; astronáutica); mito de Gyges (observador invisível que espiona a vida dos seus contemporâneos; têm-se as câmeras escondidas); mito do homem ubiquiatário (graças à técnica pode-se estar em qualquer lugar simultaneamente; a Internet); mito de Babel (motiva a procura de uma língua universal; como exemplo, tem-se as máquinas de tradução); mito da pedra filosofal (procura pelo poder de transmutar a matéria; isso se traduz no domínio dos átomos); mito da recriação do idêntico (atravessa inúmeras pesquisas, desde a alta-fidelidade à clonagem); mito do Golem (criação de seres artificiais, robôs, inteligência artificial etc). Legros et al. (2007) apontam outros como o da panacéia (medicamento universal); da viagem no tempo; da comunicação telepática; da comunicação com animais; do encontro com extraterrestres etc.

No que tange ao aspecto da ficcionalização, abordamos os elementos que engendram viabilidades no campo da ciência e alimentam a perspectiva positiva ou negativa do futuro da humanidade.

Nosso campo analítico é o de remakes de sci-fi cinematográfica cujas primeiras produções são, majoritariamente, marcadas pelo espírito de época pós II Grande Guerra e Guerra Fria.

\section{Segundo Siclier e Labarte,}

quatorze anos após a Grande Exposição Universal, a fé que o mundo tinha na ciência se transforma em desilusão amarga. Na guerra que varreu a Europa, as invenções destinadas ao progresso serviram, frequentemente, à destruição. $\mathrm{O}$ aeroplano, que conquistou o ar, se põe a lançar bombas. Os dirigíveis tornam-se máquinas hostis. Os gases asfixiantes fazem mais vítimas que os fuzis e se o automóvel, com os táxis do Marne, servem para preservar a França de uma invasão, seu derivado direto, o tanque, extermina os homens. O canhão alemão, que bombardeia Paris de longe, tem qualquer coisa daquele de Mèlies que envia os astrônomos à Lua. Bruscamente, se revela o lado nefasto de uma ciência a serviço do espírito da conquista e da barbárie. A Alemanha vencida terá, durante muito tempo, em relação a seus vizinhos mais próximos, o peso de uma maldição que ela acolherá com um complexo masoquista de culpabilidade (SICLIER \& LABARTE, 1958, p.19).

$\mathrm{O}$ misticismo e a magia eram forças ocultas às quais os alemães desse entre-guerra se entregavam com complacência e que floresceram diante da morte nos campos de batalha. "Os fantasmas que já frequentaram o romantismo alemão, reviviam tais quais sombras do Hades quando bebiam sangue" (SICLIER \& LABARTE, 1958, p.19).

Nesse contexto, os autores apresentam a efervescência do cinema expressionista alemão e a consolidação de alguns mitos como o homem artificial, pelas figuras do golum, do autômato etc. que já existiam em abundância na literatura alemã. Homonculus (1916; Otto Rippert), mostrava um cientista criando um homem artificial e "realizando assim o antigo sonho alquímico caro à Paracelso" (SICLIER \& LABARTE, 1958, p. 20). O golem da tradição judaica surge em duas produções: Der Golem (O Golem, 1914; Paul Wegener e Henrik Galeen) e Der Golem wie er in die Welt kam, (1920; Paul Wegener ${ }^{2}$ ). Les mains d'Orlac (1924; Robert Wiene) narra um estranho 
caso de um pianista que perde suas duas mãos em um acidente e, após receber por implante as mãos de um assassino, passa a ter desejos homicidas.

Segundo os autores, há no cinema alemão da época, uma tendência em exacerbar a outra metade da natureza humana, que era simbolizada, tão bem pelo homúnculo, pelo golem ou pelas mãos de Orlac. Nesse sentido, o expressionismo segue um caminho oposto ao do surrealismo, ao reforçar a cisão psíquica, ao passo que este último procurava uma reconciliação do homem com ele mesmo.

Após a II Guerra Mundial, o novo contexto sóciopolítico-ideológico parece determinar as mudanças nas representações que povoam o imaginário tecno-maquínico e a percepção de futuro do desenvolvimento científico para a humanidade.

Um evento, no dia 24 de junho de 1947, vem povoar, com novos elementos, aliados à paranóia norteamericana da invasão comunista, o imaginário que começa a se constituir.

Kenneth Arnold um homem de negócios norteamericano decide dar uma volta em seu avião particular. Ao contornar o Monte Raimei no estado de Washington ele vê aparelhos voadores em forma de disco. O mistério desses objetos começa, na imprensa, a desencadear uma série de comentários e suposições acerca de sua origem. "A opinião pública trabalhada pela imprensa começa a atribuir a esses misteriosos fenômenos uma origem bem definida" (SICILIER\& LABARTE, 1958, p.56) Começava-se a pensar que tais objetos eram construídos e enviados pelos soviéticos para observar o território americano. O clima de histeria começa a se instalar chegando, inclusive, ao Secretario de Estado de Defesa, James Forrestal, que se joga da janela em 11 de abril de 1949, crendo que o exército vermelho desceria dos céus em discos voadores.

$\mathrm{Na}$ Europa este clima não floresce, pois os países deste continente estão mais preocupados em se recuperar da guerra. Os europeus vêem nesses fatos mais um tipo de jogada propagandística dos americanos do que uma real ameaça. Afinal, se os americanos foram os primeiros a experimentar a bomba atômica, depois de um projeto secreto, eles poderiam muito bem continuar com tais pesquisas e desenvolver novos artefatos. "De qualquer forma, o perigo vem do céu e a aparição de discos voadores marca, com efeito, os primeiros sintomas da guerra fria que acometem $[\ldots]$ os dois blocos econômicos e militares mais poderosos do mundo" (SICILIER\& LABARTE, 1958, p.56).

Os autores afirmam que tais eventos habitam com novas cores o imaginário que a ficção-científica fortalece na relação entre ciência e fantasia. Afinal, se a bomba atômica, algo até então impensável em termos de poder de destruição, tornou-se uma realidade, que outros prodígios a ciência não poderia materializar? No campo da $s c i$-fi, a concretude de uma fantasia científica é uma possibilidade, o que estaria relacionado à própria dinâmica do gênero. Nesse sentido, em nossa problematização, fazemos uma intersecção com o pensamento bakhtinia- no, no qual o gênero emerge como força aglutinadora de elementos da tradição e do contexto sócio-cultural organizando-os na obra.

\section{Gênero e memória}

Mergulhar no universo de Mikhail Bakhtin exige um exercício de reordenamento dos conceitos construídos no âmbito da literatura, já que ele nos pede, constantemente, que consideremos a força do contexto sócio-ideológico na construção dos diferentes gêneros circulantes em uma dada sociedade/cultura. Por esse motivo, a exploração do conceito de gênero sob esta perspectiva abre a possibilidade de discutir as manifestações que outrora, anteriormente aos movimentos que consideravam a "cultura de baixo”, não eram consideradas como culturais, já que este conceito estava atrelado aos padrões da elite intelectual.

A conjugação das perspectivas bakhtinianas com o cinema é uma das vertentes dos estudos de Robert Stam. Em seu livro Bakhtin: da teoria literária à cultura de massa, Stam aponta para a riqueza de uma abordagem translinguística dos gêneros do discurso no cinema, conjugando os gêneros primário e secundário.

Assim, quando discutimos o conceito de gênero no âmbito da produção cinematográfica, buscamos identificar a especificidade do gênero de ficção-científica como elemento ideológico de uma memória discursiva do papel da ciência, cujas representações estão fortemente vinculadas com as questões que emergem do campo científico entrelaçadas com os aspectos míticos já discutidos.

Nas suas teorizações a partir da análise da obra de Dostoievsky, Bakhtin construiu uma concepção de gênero que extrapola o campo literário. Em A estética da criação verbal ele mostra como a riqueza e a variedade dos gêneros do discurso nos levam a pensar a impossibilidade de um campo comum para seu estudo. No entanto, ele propõe, face a esta heterogeneidade, uma forma de abordagem a partir da distinção entre gênero primário e gênero secundário. $\mathrm{O}$ primeiro seria mais simples e estaria relacionado ao espaço cotidiano, constituindo-se em circunstâncias de comunicação verbal espontânea, como a réplica ou a carta. O segundo, de natureza mais complexa (ou porque não dizer mais híbrida), absorve e transmuta os produtos verbais de gênero primário e, nesse processo, desterritorializa-os, faz com eles percam "sua relação imediata com a realidade existente e com a realidade dos enunciados alheios" (BAKHTIN, 1997, p.281). Ao gênero secundário, pertencem o romance, o discurso científico, o teatro, o discurso ideológico, enfim, produtos de "circunstâncias de uma comunicação cultural, mais complexa e relativamente mais evoluída, principalmente escrita: artística, científica, sociopolítica." (BAKHTIN, 1997, p.281).

É importante frisar que esta concepção de gênero é fruto de uma longa reflexão efetuada por Bakhtin acerca do romance. Em sua obra Questões de Estética e Literatura: a teoria do romance, Bakhtin empreende uma robusta análise dos elementos que constituem o romance, tomando como exemplo principal a obra de Dostoievsky e outros gêneros para efeitos de comparação. Segundo a nota da 
edição russa, os textos que se encontram reunidos nesta obra foram escritos por Bakhtin em épocas diferentes, o que pode explicar certa variação conceitual e mesmo terminológica entre os estudos. $\mathrm{Na}$ reflexão sobre a natureza deste gênero, o teórico russo articula questões que culminam com uma concepção histórica, social e ideológica das vozes presentes no romance. Tomemos o caso do plurilingüísmo, termo utilizado por Bakhtin para indicar o conjunto de linguagens que compõem o discurso do prosador-romancista. Ele afirma que o plurilingüismo social é a consciência da diversidade das linguagens do mundo e da sociedade (estas linguagens orquestram o tema do romance) e ele entra no romance como estilizações impessoais (que falam de outras linguagens: profissionais, sociais, de outros gêneros, etc.) ou imagens personificadas do autor convencional.

Nesse sentido, para Bakhtin, as diferentes linguagens da sociedade se materializam no romance pelas figuras das pessoas que falam ou pela ressonância especial do discurso direto do romance. Há o caso das estilizações paródicas impessoais, que podem ser como as paródias utilizadas pelos humoristas ingleses e alemães; ou pode aparecer sob o aspecto de gêneros intercalados (poesia; narrativa histórica) atribuídos a outros autores supostos; ou pelo discurso incontestável do autor - se é polêmico ou apologético. Todas estas manifestações/linguagens quando não estão encarnadas em um personagem, são concretizadas sobre um plano social e histórico mais ou menos objetivado. Por isso, há um plano histórico e ideológico sobre o qual o personagem age e vive e fala, e para Bakhtin, o problema central da estilística do romance é o problema da imagem da linguagem; o problema da representação literária da linguagem. Temos, então, uma linguagem social e historicamente construída cuja representação em um outro produto textual implica, necessariamente, uma transformação e tal representação está na base de sua concepção de gênero. O gênero reflete as mudanças sociais e, de forma retroativa, um novo gênero literário, quando emerge, procura "ensinar" a se ver os aspectos da realidade sob uma nova forma (MORSON \& EMERSON, 1990, p.277).

O gênero como agenciador de elementos de uma memória para um determinado campo cultural é extremamente rica e complexa, pois ele passa a funcionar como um ordenador de características, traços ou manifestações de natureza social e permite que elas se condensem em um material cultural qualquer (romances, filmes, pinturas, etc.).

A partir das teorizações de Bakhtin, é possível perceber que sua idéia de gênero está mais relacionada a como as formas do discurso socialmente produzidas se materializam em um determinado produto cultural do que ao um conjunto de traços que caracterizam uma obra. De outra forma: com a problemática de Bakhtin, o gênero passa a ser um elemento importante para a compreensão de formas sócio-ideológicas de produtos culturais.

Os filmes de ficção-científica são produtos culturais ideologicamente marcados pela indústria cinematográfica, que gera os textos fílmicos, e pelas representações ideológicas da ciência que marcam a civilização ocidental desde a Revolução Científica.

Nesse sentido, o termo gênero cinematográfico deve ser entendido a partir do contexto de produção do produto fílmico, a indústria do cinema, que, por sua vez, constrói seus produtos textuais com uma linguagem de natureza híbrida, que, na origem, mesclou som, imagem em movimento e gêneros literários. É dessa forma que, usualmente, se faz referência aos gêneros literário, cinematográfico, científico, etc., cada qual produzido em um sistema específico, que organiza os traços sócioideológicos que marcam suas produções.

No que concerne à ficção-científica, vou buscar em um dos mais renomados escritores e teóricos desse gênero, Issac Asimov, os elementos necessários para compreender sua formação tanto no campo literário quanto no campo cinematográfico.

Asimov é um cientista na concepção que a Revolução Científica nos legou. Sua formação acadêmica em Bioquímica o levou ao trabalho docente e sua paixão por histórias de ficção-científica o transformou em um escritor de notoriedade e, também, em um teórico que procurou delimitar algumas questões para uma área que ainda não era bem vista pelos críticos.

A ficção-científica (s.f., na forma abreviada utilizada por Asimov), no seu entender, só teve oportunidade de surgir com o advento da ciência moderna, pois somente a partir desse momento, foi possível conceber a relação entre as mudanças sociais e técnico-científicas e, também, foi possível se pensar em constituir uma trama com base em teorias e proposições científicas. Suas definições de ficção-científica encontram-se espalhadas pelas inúmeras resenhas e artigos que escreveu para revistas especializadas. Nelas, observa-se a preocupação em distinguir o gênero de outros mais antigos, como a literatura fantástica, surrealista, de horror e de aventuras. O traço distintivo mais característico, no caso da s.f., é a ligação com os fatos cientificamente comprovados que se desenvolvem no tempo presente da produção da história e a articulação dos avanços científicos e tecnológicos com as mudanças que se operam no universo criado na história. Assim, em uma de suas definições ele procura distinguir s.f. de outras narrativas, ele afirma que

os acontecimentos supra-reais da história, na ficção científica, podem ser concebivelmente derivados do nosso próprio meio social, mediante adequadas mudanças ao nível da ciência e da tecnologia. Tais mudanças representarão um avanço, como o estabelecimento de uma colônia em Marte ou a interpretação bem-sucedida de sinais enviados por formas de vida extraterrestres. Constituirão um retrocesso, a exemplo de algum estudo sobre o aniquilamento de nossa civilização tecnológica, provocado por um desastre nuclear ou ecológico. Admitida uma interpretação liberal do conceito do progresso científico que possa ser alcançado, é lícito incluir na ficção científica temas não tão prováveis como as viagens através do tempo, as velocidades superiores à da luz, e assim por diante (ASIMOV, 1984, p.16).

Ele enfatiza que a velocidade das mudanças que afetam a vida dos homens só passou a ser percebida no 
decurso de uma vida, a partir desse avanço tecnológico. Isso foi fundamental, também, para que a noção de futuro se transformasse.

Com tal visão sobre a s.f., Azimov estabeleceu distinções de vocabulário (robôs, andróides, autômatos, monstros, etc.) e tipologia (o cientista como vilão apresenta diferentes características: há os presunçosos; os loucos; os perversos; os arrogantes, etc.), além de delinear temáticas mais afeitas ao gênero, que ele denomina de sonhos da ficção científica (viagens no tempo; ação sobre os clones; transferência de massas; aldeia global; governo mundial; controle da evolução; seres biônicos; robôs; fontes permanentes de energia).

Sua preocupação com o caráter pedagógico da s.f. levou-o a classificar com extremo rigor as obras do gênero, considerando a potencialidade que as histórias de s.f. podem ter na divulgação científica. Daí, não ser surpreendente, que a s.f. seja entendida na sua relação com a ciência: "a expressão ficção científica diz respeito a histórias que são limitadas pela ciência" (ASIMOV, 1984, p. 26-27).

$\mathrm{O}$ rigor com o qual encarava o gênero levou-o a não considerar as produções cinematográficas de ficção científica como exemplares do mesmo quilate do gênero literário. Para ele, os filmes de s.f. abusavam de efeitos especiais para compensar a pobreza da história.

É importante ter em vista que as produções cinematográficas operam em um outro sistema de produção simbólica e afetam, não uma outra camada do público, mas uma outra esfera de consumo: o leitor de s.f. também é um potencial espectador de filmes de s.f.; mas as formas de consumo e a relação com estes dois tipos de textos culturais podem ser diferenciadas.

Os filmes, assim como o texto escrito, ao surgirem, inauguraram uma nova forma de leitura e de produção de sentidos. A conjugação de alguns fatores permitiu que o texto fílmico fosse produzido e comercializado como um produto, mas sem ter, nesse processo, perdido seu caráter cultural-ideológico. O que talvez tenha se omitido foram as conseqüências de sua circulação por meios culturais e ideológicos diferenciados.

A ficção-científica já se constituía como gênero quando da sua "chegada" ao campo da produção cinematográfica. Seu potencial de circulação é, então, aumentado, em virtude da própria característica da indústria do cinema. No entanto, a disseminação e consumo de produtos culturais diferenciados traz conseqüências de natureza econômica e social, que, no meu trabalho, são potencializadas pelo fenômeno do remake, que ao produzir novamente filmes já produzidos, trabalha na dinâmica do novo e do antigo: reagencia elementos da antiga produção e introduz elementos novos nesse contexto.

No caso específico deste estudo, os filmes de ficçãocientífica são caracteristicamente ligados ao contexto histórico-ideológico de produção. Refilmagens garantem a rediscussão de temáticas antigas em contextos sociais com novas preocupações, o que pode indicar uma manutenção e adaptação da imagem da ciência moderna, tal como se formou e consolidou com a Revolução Científica, ou uma posição crítica sobre as conseqüências que sua visão de mundo implantou. Nesse sentido, a discussão coloca em jogo o projeto de modernidade e, também, a constituição de uma memória, que atualmente denomino discusivo-cinematográfica.

\section{A informação não-científica sobre a ciência}

A problematização da informação não-científica sobre a ciência tomou como marco inicial ou de filiação teórica as propriedades da informação científica, conforme Mikhailov, Chernyi, Gilliarevskii, sobretudo aquelas que têm mais relação com o nosso tipo de informação: $o$ valor da informação científica, a natureza social da informação científica e a dispersão da informação científica. Estas três e as demais propriedades foram estabelecidas no contexto do campo científico, ao passo que o nosso tipo de informação deve considerar dois campos: o científico e o ficcional. Nossa opção foi, mais do que considerar tais dimensões, entender a relação que se dá entre elas; entre os elementos do campo ficcional e do campo científico. Como eles alimentam as imagens que se constróem e sustentam a disseminação de teorias científicas amalgamadas a um imaginário tecno-maquínico. Nesse sentido, situamos no campo ficcional a constituição de um imaginário científico que trabalha com elementos míticos e fantásticos que já habitam o imaginário humano ocidental, ao passo que no campo científico, já estão demarcados os elementos da produção e circulação do conhecimento.

Inicialmente, a informação científica, assim como a não-científica, não deve ser confundida com os elementos que a compõem. Para Mikhailov et al, um documento científico é um quantum da informação científica. Assim, um filme de $s c i-f i$ pode ser entendido como uma parte de uma informação não-científica sobre a ciência, cujos elementos estão organizados tanto no campo da ciência quanto no da ficção para refletir (no sentido em que os autores tomam o termo reflexão, conforme a teoriozação leninista-marxista) em uma materialidade específica, uma mensagem associada a um contexto de época.

Se retomarmos a propriedade que os autores consideram a mais importante, $o$ valor da informação, podemos estabelecer que o valor da informação não-científica reside, em princípio, no seu potencial de popularização da ciência, por oportunizar espaços de discussão pública a partir da análise da constituição de um imaginário científico pautado nos problemas decorrentes do avanço inconseqüente dos rumos da ciência e por redimensionar a discussão acerca da informação no campo da cultura. Ao funcionar no processo de constituição das narrativas filmico-informacionais, este tipo de informação indica, no horizonte da memória, como as representações sobre a ciência se formam, transformam e sustentam visões de mundo. Assim, o valor de uma informação que não é científica, mas que informa sobre ciência, decorre do redimensionamento dos espaços de aprendizagem e dos 
conteúdos: o conhecimento se constrói a partir de outras vivências além daquelas experenciadas no espaço formal de educação e de outras narrativas que não aquelas da racionalidade científica.

Outra propriedade delineada pelos autores, natureza social da informação científica, vincula-se à cognição humana e da sociedade, à comunicação e ao espaço no qual se constitui um repertório de elementos simbólicos que é comum a todos os indivíduos e que alimenta nossas representações e, também, ao desejo de acúmulo e preservação das informações em um conjunto de materialidade que constituiria o "tesouro do conhecimento humano”. A informação não científica sobre a ciência tem sua natureza social marcada pela sua circulação e consumo no sistema cultural, assim como pela sua carga simbólica que entra na construção das representações sobre ciência e no repertório de memória científica. Tal memória parece estar sustentada pelo princípio que rege a memória do gênero, noção bakhtiniana que preconiza a função do gênero como órgão de memória, ao trazer os componentes vitais ao nascimento de uma obra dentro de uma determinada corrente ou referencial de produção.

Outrossim, considerando mais uma propriedade estabelecida pelos teóricos russos, dispersão da informação científica, alargamos o campo de possibilidades, pois as noções, declarações de fatos, hipóteses, conceitos, etc. que constituem as unidades semânticas da informação científica estão, em nossos textos de ficção, sendo trabalhadas e retrabalhadas em consonância com a ação do binômio permanência-novidade. Nos remakes de sci-fi, a "nova vida" que elas (cf. Mikhailov et al) adquirem estaria ligada a essa dinâmica.

A partir deste ponto, e considerando todas as análises efetuadas (principalmente sobre as materialidades fílmicas, mas, também, sobre as críticas) podemos afirmar que a informação não-científica sobre a ciência tem suas propriedades estabelecidas, principalmente, a partir do que denominamos sua dupla natureza: científica e ficcional. Por conta desta dupla natureza, a informação não científica sobre a ciência se caracteriza pelo amálgama da informação científica com elementos, em geral, relacionados ao campo do mito e do imaginário. Com isso, podemos apontar que tais propriedades se situam em uma dinâmica que envolve a divulgação do saber científico e a referenciação a elementos culturais. Em decorrência de sua natureza científica, ela também apresenta algumas das propriedades que Mikhailov, Chernyi e Gilliarevskii já haviam estabelecido para a informação científica.

Os textos fílmicos que constituem uma família de remakes têm seus sentidos construídos contingentemente nas relações que mantêm entre si e com os contextos de produção, sendo a informação o elemento de natureza sócio-cultural que sustenta tais relações. No âmbito da produção e recepção, as informações que possibilitam a elaboração e entendimento dos remakes acionam os significados relacionados a diferentes instâncias, dentre as quais aquela que os gera e a diegese narrativa. A informação não-científica está, dessa forma, no trânsito entre pólos diferenciados, mas relacionados, de significação, da mesma forma como é definida a informação na sua relação com o conhecimento, pois "ela está ligada a visões sobre o conhecimento ao mesmo tempo em que as influencia e modifica” (BRESCHER \& CAFÉ, 2008, p.4). Nessa relação, nosso tipo de informação tem o potencial de impacto na alteração do conhecimento que, por sua vez, tem um caráter dinâmico, tendo na informação uma forma material de sua existência (BRESCHER \& CAFÉ, 2008). Em alinhamento com tal perspectiva é que pensamos o nosso tipo de informação.

Para análise foi desenvolvido um instrumento analítico que compreende três grandes dimensões: a dimensão textual/narrativa, que vai demandar um delineamento do filme como texto e narrativa; a dimensão documental, que implica na percepção do filme como documento informacional; a dimensão contextual, que coloca o filme como produto de um contexto específico de produção. Além dessas três dimensões, ela apresenta uma parte inicial, denominada identificação, na qual são descritas as informações referentes à produção do texto fílmico. As informações são reorganizadas em função do referente e da personagem das narrativas de sci-fi, de modo a salientar as mudanças e as permanências de uma versão à outra. No presente artigo, apresentamos as análises de duas famílias de filme, conforme o Quadro a seguir.

\section{Quadro - Família de filmes analisados.}

$$
\begin{aligned}
& \text { Família de } \\
& \text { Guerra dos } \\
& \text { Mundos } \\
& \text { The War of the Worlds (Byron Haskin, 1952) } \\
& \text { War of the Worlds (Steven Spielberg, 2005) }
\end{aligned}
$$

A Tabela indica, a partir das análises efetuadas, os elementos de permanência e mudança, considerando tanto as informações representadas em nível ficcional quanto aquelas que estão representadas em nível informacional. 
A personagem principal é Clayton Forrester, um astrofísico que traz as explicações plausíveis para todos os eventos, e aponta os limites da tecnologia

Guerra dos Mundos humana no combate a uma força extraterrestre (Byron Haskin, 1953) superior. Forrester também se vê diante de uma ameaça que consegue explicar, entendendo que somente mais pesquisas ligadas à aplicação bélica podem ajudar o Planeta.
A ciência é um discurso lógico e verdadeiro, o que transforma aquele que o domina em uma figura central na trama. Ela também está na base do desenvolvimento técnico-militar que pode levar o homem à solução do problema da invasão.
Guerra dos Mundos (Steven Spielberg, 2005)
A personagem principal é Ray Ferrier, homem médio norte-americano, trabalhador, divorciado. Ele, junto a outras centenas de pessoas, constata o poder destruidor dos invasores. Ele domina um saber técnico especializado, advindo de sua experiência profissional (conforme a economia narrativa nos permite intuir) que é suficiente para sustentar sua ação de sobrevivência ao longo da jornada.
Não há discurso nem prática científica. A ciência não é mencionada, nem mesmo como possível campo a oferecer uma solução ou para tentar explicar o que ocorre.

Mudança: A mudança principal de uma versão a outra decorre do perfil da personagem principal, que parece determinar o declínio do papel da ciência do filme-gerador à segunda versão. Sem cientista, a ciência também perde seu espaço. A primeira versão tem seu foco na ação dos cientistas e das possibilidades armamentistas oriundas das pesquisas nucleares. Grupos bem delimitados estão representados: o religioso, o militar e o científico. Eles estão em ação conjunta, mas com visões diferenciadas acerca do invasor. A segunda versão oferece um panorama diferenciado da invasão, a partir da perspectiva particular do sujeito comum. Sem discutir porque e de onde vieram e como combatê-los, a segunda versão coloca a luta pela sobrevivência em destaque, emergindo o saber comum como elemento importante no processo.

Permanência: Apesar do perfil diferenciado das personagens principais e da trajetória de ambos na dinâmica narrativa, a impotência humana diante da invasão é mantida, assim como a solução final: os extraterrestres morrem devido a uma contaminação bacteriológica.

\section{A Máquina do \\ Tempo}

(George Pal, 1960)
A personagem principal, George, é um cientista de fins do século XIX. Sua característica principal é a crença na ciência, no seu potencial de desenvolver uma sociedade melhor e mais esclarecida. Ele desenvolve a máquina do tempo para comprovar sua idéia de que no futuro, devido aos avanços da ciência, a humanidade viveria bem melhor.
A ciência é um campo ilimitado e potencialmente positivo. Ela possibilitou o desenvolvimento da máquina do tempo e poderá auxiliar, no futuro, no resgate da uma humanidade perdida.

A ciência é um campo de saber que possibilita o Alexander Hartdegen é cientista e professor universitário. Ele desenvolve a máquina do tempo para tentar reverter um problema pessoal: o assassinato da mulher que ama. Suas viagens não têm sucesso e ele começa a se indagar sobre a impossibilidade de, a partir do passado, mudar o futuro.

desenvolvimento tecnológico-informacional, mas não oferece respostas a determinadas questões, principalmente as existenciais. No entanto, é justamente a perda desse saber acumulado pela humanidade que determina um futuro sombrio para civilização humana.

Mudança: George e Alexander são movidos por interesses diferenciados. O primeiro procura a comprovação de uma hipótese; o segundo, a solução para uma questão referente ao destino humano e ao tempo. Tal mudança determina, também, uma visão diferenciada de ciência. Na primeira versão ela é celebrada; na segunda, uma instância importante para se buscar soluções para alguns problemas. Na segunda versão, determinados aspectos do fazer científico são mais destacados, principalmente aquele referente à informação científica.

Permanência: O futuro da humanidade é a degradação. Dois grupos humanos lutam pela sobrevivência: um caçando o outro. Não se trata de um domínio sócio-econômico. Os morlock são canibais e os eloi a presa. Em ambas as versões, o cientista decide não retornar ao seu tempo e viver no futuro, tentando tirar os eloi dessa condição. A figura feminina é um dos fatores que prende o cientista no futuro. 
Em princípio, a informação não-científica sobre a ciência tem sua natureza determinada pelas mudanças nas imagens de ciência e do cientista. Ao declínio ou apogeu da primeira parece seguir a segunda, o que é mais evidente no caso de Guerra dos Mundos. A ausência do cientista como protagonista e da ciência como referente discursivo leva a uma sci-fi sem ciência, o que pode ser um paradoxo. Tais mudanças são indicadores de uma dispersão que se vincula ao contexto sócio-histórico e ideológico da própria ciência: do seu status no passado à rediscussão de seu papel e de seu peso como campo de saber principal na contemporaneidade.

No entanto, considerando todas as análises realizadas, pudemos estabelecer que além dessa dupla natureza, a informação não-científica sobre a ciência tem em sua análise, principalmente em nível representacional, uma forte relação com o contexto sócio, histórico e cultural do período de produção do texto fílmico analisado. Em nível informacional, contemplado principalmente pelo campo identificação e, em parte, pela dimensão textual/ narrativa, é possível afirmar os vínculos entre as diferentes produções fílmico-informacionais. Nesse sentido, essa dupla natureza determina os modos pelos quais ela se produz, circula e afeta aqueles que a "consomem". Além disso, ela informa sobre questões científicas que só se tornam viáveis, ou verossímeis, pela ficcionalização, o que dinamiza seu potencial para o campo da popularização da ciência. O que nos leva a uma aproximação com uma das propriedades dos citados autores russos, a do valor da informação científica.

Nesse sentido, sua natureza social é marcada não somente pela sua função na circulação de imagens impregnadas de significado acerca da ciência, mas, também, pelo seu potencial de sustentar com seus elementos uma memória de e para a ciência. Tal memória parece estar sustentada pelo princípio que rege a memória do gênero, noção bakhtiniana que preconiza a função do gênero como órgão de memória, ao trazer os componentes vitais ao nascimento de uma obra dentro de uma determinada corrente ou referencial de produção.

A forte relação das obras ficcionais com o contexto de produção determina que a informação não-científica sobre a ciência tenha suas propriedades analisadas tendo em vista a condição de produto cultural de massa das narrativas cinematográficas de sci-fi. Além disso, outro determinante a ser considerado no delineamento dessas propriedades é o delicado equilíbrio que tais narrativas apresentam entre as questões científicas exploradas como viabilidades e a ficcionalização, que se alimenta do imaginário tecno-maquínico construído ao longo da trajetória da própria ciência em nossa história.

\section{Notas}

1. Há divergência quanto a este ano. O Internet Movie Data Base (IMDB) aponta 1915.

2. No IMDB há outro direto junto com ele: Carl Boese.

\section{Referências bibliográficas}

ASIMOV, I. No mundo da ficção científica. Rio de Janeiro: Francisco Alves, 1984.

BAKHTIN, M. Estética da criação verbal. São Paulo: Martins Fontes, 1997.

BAKHTIN, M. Questões de literatura e estética: a teoria do romance. São Paulo:HUICETEC, 1988.

GABRIEL, E. E. L'imaginaire des mondes virtuels. Imaginaire \& Inconscient 2002- 3 (no 7), | p 107-118.

LEGROS, P.; MONNEYRON, F.; RENARD, J.-B.; TACUSSEL, P. Sociologia do imaginário. Porto Alegre: Sulina, 2007.

MIKHAILOV, A. I.; CHERNIY, A. I.; GILYAREVSKYI, R. S. Estruturas e Principais Propriedades da Informação Científica. In: GOMES, Hagar Espanha (org.) Ciência da informação ou informática? Rio de Janeiro: Editora Calunga, Série Ciência da Informação, 1980.

MORSON, G. S.; EMERSON, C. Mikhail Bakhtin: creation of a prosaics. California: Stanford University Press, 1990.

SICLIER, J.; LABARTHE, A. S. Images de la sciencefiction. Paris: Éditions du Cerf, 1958. Col. 7e. Art.

STAM, R. Bakhtin: da teoria literária à cultura de massa. São Paulo: Ática, 2000.

TIME machine, the. Direção George Pal. EUA: George Pal Productions, 1960. 103 min, son, color.

TIME machine, the. Direção Simon Wells. EUA: Warner Bros, 2002. 96 min, son, color.

WAR of the Worlds, the. Direção Byron Haskin. EUA: Paramount, 1952. 85 min, son, p\&b.

WAR of the Worlds, the. Direção Steven Spielberg. EUA: Paramount, 2005. 116 min, son, color.

\section{Sobre o autor}

\section{Carmen Irene C. de Oliveira}

Carmen Irene C. de Oliveira é graduada em Letras pela UFRJ, mestre em Memória Social, pela UNIRIO, e atualmente é doutoranda em Ciência da Informação pelo IBICT/UFF. Atua como pesquisadora nos Grupos de Pesquisa (CNPq) Educação, Discurso e Mídia e Memória, Informação, Discurso e Ciência. Pesquisa, com investigações que focalizam a divulgação científica, a educação científica, informação e linguagem. 